\title{
Dose-related beneficial and harmful effects of gabapentin in postoperative pain management - post hoc analyses from a systematic review with meta-analyses and trial sequential analyses
}

This article was published in the following Dove Press journal: Journal of Pain Research

I November 2017

Number of times this article has been viewed

\author{
Maria Louise Fabritius' \\ Jørn Wetterslev ${ }^{2}$ \\ Ole Mathiesen ${ }^{3}$ \\ Jørgen B Dahl'
}

'Department of Anaesthesiology and Intensive Care, Bispebjerg and Frederiksberg Hospitals, Copenhagen, Denmark; ${ }^{2}$ Copenhagen Trial Unit, Centre for Clinical Intervention Research, Copenhagen University Hospital, Copenhagen, Denmark; ${ }^{3}$ Department of Anaesthesiology, Zealand University Hospital, Køge, Denmark
Background: During the last 15 years, gabapentin has become an established component of postoperative pain treatment. Gabapentin has been employed in a wide range of doses, but little is known about the optimal dose, providing the best balance between benefit and harm. This systematic review with meta-analyses aimed to explore the beneficial and harmful effects of various doses of gabapentin administered to surgical patients.

Materials and methods: Data in this paper were derived from an original review, and the subgroup analyses were predefined in an International Prospective Register of Systematic Reviews published protocol: PROSPERO (ID: CRD42013006538). The methods followed Cochrane guidelines. The Cochrane Library's CENTRAL, PubMed, EMBASE, Science Citation Index Expanded, Google Scholar, and FDA database were searched for relevant trials. Randomized clinical trials comparing gabapentin versus placebo were included. Four different dose intervals were investigated: 0-350, 351-700, 701-1050, and >1050 mg. Primary co-outcomes were 24-hour morphine consumption and serious adverse events (SAEs), with emphasis put on trials with low risk of bias.

Results: One hundred and twenty-two randomized clinical trials, with 8466 patients, were included. Sixteen were overall low risk of bias. No consistent increase in morphine-sparing effect was observed with increasing doses of gabapentin from the trials with low risk of bias. Analyzing all trials, the smallest and the highest dose subgroups demonstrated numerically the most prominent reduction in morphine consumption. Twenty-seven trials reported 72 SAEs, of which $83 \%$ were reported in the $>1050 \mathrm{mg}$ subgroup. No systematic increase in SAEs was observed with increasing doses of gabapentin.

Conclusion: Data were sparse, and the small number of trials with low risk of bias is a major limitation for firm conclusions. Taking these limitations into account, we were not able to demonstrate a clear relationship between the dosage of gabapentin and opioid-sparing or harmful effects. These subgroup analyses are exploratory and hypothesis-generating for future trialists Keywords: gabapentin, 1-(aminomethyl)cyclohexaneacetic acid, analgesic, postoperative pain management, dose effect

\section{Introduction}

During the last 15 years, gabapentin has become an established component of postoperative analgesia. Gabapentin has been employed in a wide range of doses, but little is known about the optimal dose, providing the best balance between benefit and harm in postoperative pain treatment.
Department of Anaesthesiology and Intensive Care, Bispebjerg and Frederiksberg Hospitals, Bispebjerg bakke 23, 2400 Copenhagen, Denmark Tel +4560179531

Email malou_fabritius@dadlnet.dk 
The number of published, dose-finding gabapentin trials in postoperative pain treatment is limited, ${ }^{1-11}$ and the results are inconsistent. It is well established, however, that oral gabapentin is absorbed in part by diffusion and in part by a carrier-mediated saturable transport mechanism system. ${ }^{13}$ Thus, the bioavailability of oral gabapentin is not linear, but inversely dependent on the dose, ${ }^{14}$ ranging from $\sim 60 \%$ for a $300 \mathrm{mg}$ dose to $\sim 30 \%$ with doses of $1600 \mathrm{mg} \cdot{ }^{14-16}$

Consequently, the optimal dosing of gabapentin, providing the best balance between benefit and harm, may not be obvious. In this post hoc subgroup analysis, we aimed to explore the relative effects of different doses of gabapentin on 24-hour morphine consumption, pain intensity, risk of serious adverse events (SAEs), and other adverse events.

We hypothesized that increasing doses of gabapentin would lead to increased reduction in 24-hour morphine consumption and/or pain intensity, decreased adverse effects, and probably also increased risk of SAEs and other drug-specific adverse events. We realized, however, that the possible increase in beneficial and harmful effects with increasing doses of gabapentin would probably not be linear due to the nonlinear bioavailability of oral gabapentin.

\section{Materials and methods}

This review includes exploratory post hoc analyses from an original systematic review, employing the Cochrane Collaboration methodology. The protocol of the original PRISMA-compliant review is published in the International Prospective Register of Systematic Reviews website (www.crd.york.ac.uk/PROSPERO) with the registration no. CRD42013006538. ${ }^{17}$

\section{Literature search}

Our comprehensive search strategy was planned by a trial search coordinator and reported in the published systematic review ${ }^{18}$ and Supplementary material S1: search strategies.

The Cochrane Library's CENTRAL, PubMed, EMBASE, Science Citation Index Expanded, Google Scholar, and FDA database, and reference lists of trials were searched for relevant trials. Unpublished trials were searched in relevant databases.

Randomized clinical trials comparing gabapentin versus placebo, irrespective of publication type, status, publication year, and language, were included. All non-English articles were translated to English. We updated the search strategy on April 12, 2016.

\section{Data}

MLF and one of the independent authors (AG, MSH, PLP, LN) screened the titles and abstracts, evaluated the risk of bias, and extracted data. Extracted data included article publication year, number of participants, surgical procedure, follow-up period and gabapentin dose administered, consumption of morphine (intravenous morphine based on equivalency, Supplementary material S2) and other nonopioid analgesics, pain intensity, and any adverse effects reported, including SAEs.

Pain intensity was reported in different scales in the original trials. All pain intensity scales using intensity scores between 0 and 10 were converted to the visual analog scale (VAS) $0-100 \mathrm{~mm}$.

If data were incomplete or bias assessment was unclear, the corresponding author was contacted. This contact was repeated after 2 weeks in case of no response to initial contact. If the corresponding author did not reply, the involved bias domains were classified as unclear.

\section{Assessment of risk of bias}

The risk of bias assessment adhered to the Cochrane Handbook methodology. ${ }^{20}$ All the included trials were assessed as low, unclear, or high risk of bias using the six bias domains described in the handbook. The "other" bias domain consisted of financial and confirmatory bias evaluations. ${ }^{21}$ Any difference in evaluations between authors on any part of the data extraction and evaluations process was solved by OM, JBD, or JW.

It was protocolled that the review and conclusions would primarily be based on trials with low risk of bias.

\section{Small trial size}

This post hoc analysis assessed the number of patients included in each original trial as defined in the original systematic review. ${ }^{18}$ Trials with less than 50 participants were defined as small trials, trials with more than 50 participants in each group formed the second group, and the trials with more than 200 participants made up the final group.

\section{Analyses}

The dose treatments of gabapentin were divided into four groups: 0-350, 351-700, 701-1050, and more than $1050 \mathrm{mg}$. The defined groups represent the four most commonly used dose treatments in gabapentin research, which are 300, 600, 900, and $1200 \mathrm{mg}$.

All doses are considered as 24-hour treatments, regardless of single or multiple administrations, pre- or postoperative treatments, or the duration of the treatment. 
If an original trial investigated more than one dose, the control group receiving placebo was divided into the corresponding number of intervention groups. The trials in which the divided control groups included less than 20 participants were excluded. The individual dose-finding trials were counted as one trial in all summary statistics. Whenever the trials were included in cumulative analyses, the trials were viewed as separate trials.

\section{Outcomes}

Twenty-four-hour morphine consumption represented the beneficial primary outcome, and SAEs represented the harmful primary outcome. SAEs were classified according to the International Conference of Harmonization - Good Clinical Practice definitions: medical events being either life-threatening, resulting in death, disability, or significant loss of function, or causing hospital admission or prolonged hospitalization. ${ }^{18}$

The secondary outcomes were divided into beneficial outcomes: reduction in early (6-hour) and late (24-hour) pain postoperatively, both at rest and during mobilization, and harmful outcomes: all other adverse events.

\section{Statistical analysis}

Review Manager (RevMan; computer program), Version 5.1.6 was used in the cumulated analyses and subgroup analyses.

The handling of median and range (or interquartile range), longer ordinal scales, and dichotomous data, examination of heterogeneity, employment of fixed- or random-effect models, Peto's odds ratio (OR), and handling of few and rare events were done according to the International Prospective Register of Systematic Reviews published protocol and is described in the published PRISMA-compliant systematic review. ${ }^{17,18}$

If more than one trial was included in the outcome, the estimates were pooled in meta-analyses and test for subgroup analyses was performed using RevMan in which the method to test for subgroup differences was implemented.

All trials with one intervention group and one control group were included. Handling of trials investigating more than one dose is described above. The mean and standard deviations were divided according to the methodology described in the Cochrane Handbook. ${ }^{20,22}$

Trial sequential analysis (TSA) was used to adjust for sparse data and repetitive testing in the cumulative analyses..$^{23,24}$ Minimal relevant clinical differences were defined as in the published systematic review. ${ }^{18} \mathrm{TSA}$ is only reported if the accrued information size was $5 \%$ or more of the required information size (RIS), since the TSA program is only able to report trial sequential monitoring boundaries if this is the case.

\section{Results}

In the original published systematic review, 19,137 titles were located, and after removal of duplicates, 16,303 titles were screened for inclusion and exclusion criteria. The original systematic review included 135 randomized clinical trials, including 3 observational studies. ${ }^{18}$

For the purpose of this review, the 3 observational studies, and 10 dose-finding trials with less than 20 patients in the split control groups, were excluded, ${ }^{1-4,6,7,8,10,11,25}$ leaving 122 trials with 8466 participants for analyses (Supplementary material S3: trial characteristics). ${ }^{5,9,19,25-143}$

\section{Trial characteristics}

In these analyses, 16 trials demonstrated overall low risk of bias, $5,9,35,41,55,58,62,76,91,95,107,108,127,128,14036$ trials showed

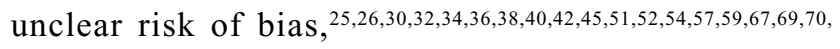
$73-75,79,84,86,88,99,100,101,103,119,122,124,125,130,139,141,143$, and 70 showed high risk of bias (Figure 1; Supplementary material S4: risk of bias graph). $6,8,12,19,27-29,31,33,37,39,43,44,46-50,53,56,60,61,63-66,71,72,77,78$, $80-83,85,87,88,90,92-94,97,99,102,105,106,109-118,120,121,123,124,126,129,131,132,134-138,142$

We found that 105 trials were "small trials", ${ }^{12,25-27}$, 29-43,45,47-61,63,65-75,77-84,86-94,96-101,104-106,109-127,131-142 14 trials included more than 50 participants in each group, ${ }^{9,19,28,44,46,62}$ $, 76,85,95,107,108,128,130,143$ and only 2 trials included more than 200 participants..$^{5,102}$

Treatment with gabapentin included both single-dose

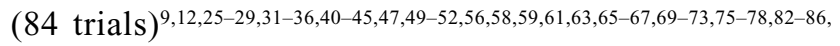
$88,90-94,96,97,99,102-106,109,111-118,120-122,124,125,128-131,133,136,138,139,143$

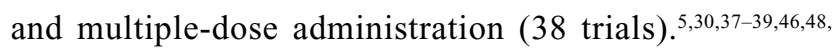
53-55,57,60,62,68,74,79-81,89,95,98,100,101,107,108,110,119,123,126,127,132,134,135,137,140-142 For further information about the individual trials, see Supplementary material S3: trial characteristics.

\section{Primary outcomes}

\section{Total 24-hour morphine consumption}

Sixty-five trials with 4851 patients reported 24-hour opioid consumption, and 15 trials (1318 participants) were classified as overall low risk of bias.

\section{Trials with low risk of bias}

In the $0-350 \mathrm{mg}$ subgroup, a reduction in 24-hour morphine consumption of $2.2 \mathrm{mg}(0.1,4.4 ; p=0.04)^{9,140}$ was reported with gabapentin versus control. The $351-700 \mathrm{mg}$ 


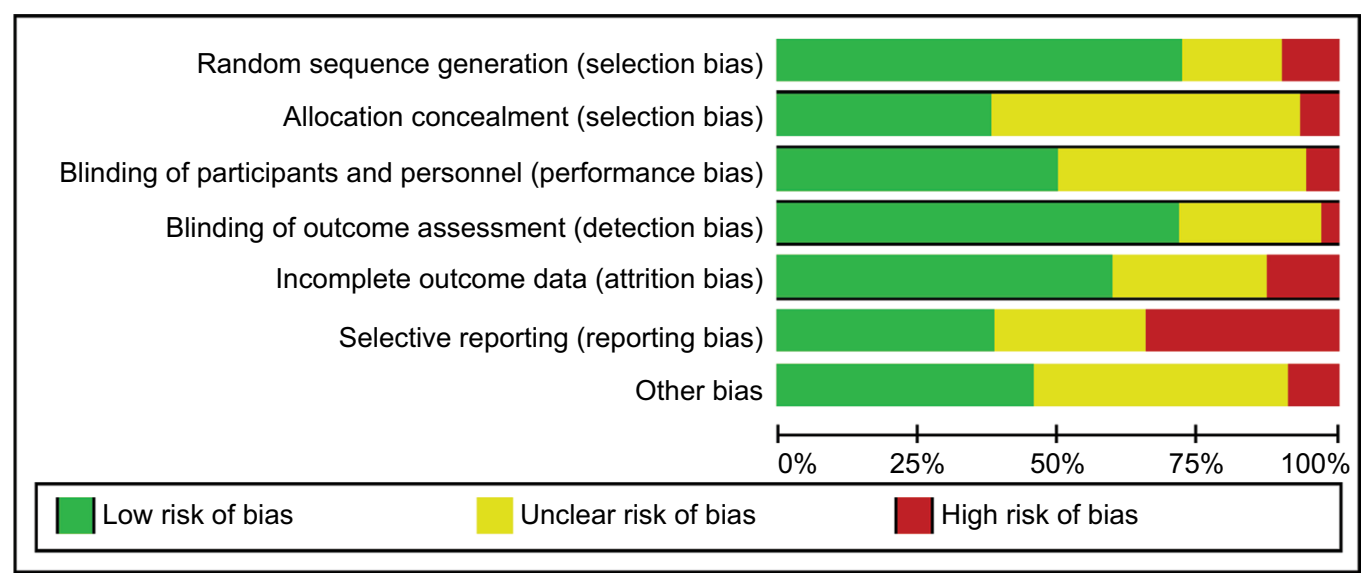

Figure I Bias evaluation of the six bias domains.

Note: The "other" bias domain consists of an evaluation of financial and confirmatory bias.

subgroup demonstrated a reduction of $3.4 \mathrm{mg}(0.9,8.5$; $p=0.12),{ }^{9,91,95,96,107,108,128}$ the $701-1050 \mathrm{mg}$ subgroup an increase in consumption of 24-hour morphine consumption of $1.1 \mathrm{mg}(0.3,2.0 ; p=0.01), 5,41,55,58,62$ and the subgroup $>1050 \mathrm{mg}$ reported a reduction of $2.9 \mathrm{mg}(-1.1,6.9 ; p=0.2)$, as shown in Table 1 and Figure 2.,51,55,62

The test for subgroup differences was significant for the 701-1050 mg subgroup compared with the other subgroups ( $p=0.002$ ), but no systematic increase in morphine-sparing effect was observed with increasing doses of gabapentin. With TSA, half the subgroup meta-analyses reached the futility area with the predefined minimal clinical difference and alpha and beta, while the other half did not report firm results (Table 1).

\section{All trials}

All subgroups demonstrated a reduction in 24-hour morphine consumption (Table 2 and Figure 3). Differences between the different dose intervals were statistically significant in test for subgroup differences between the 350-700, 701-1050 $\mathrm{mg}$, and $>1050 \mathrm{mg}$ subgroups. The $0-350 \mathrm{mg}$ subgroup and the $>1050 \mathrm{mg}$ subgroup demonstrated numerically most pronounced reduction in morphine consumption, but no systematic increase in morphine-sparing effect was observed with increasing doses of gabapentin. Only the meta-analysis for the subgroup 701-1050 did not report firm evidence according to TSA (Table 1).

\section{SAE}

Twenty-seven trials with 1958 participants reported 72 SAEs, of which $83 \%$ were reported in the $>1050 \mathrm{mg}$ subgroup. Of the 27 trials, 8 were classified as overall low risk of bias, $5,9,41,62,76,107,128,140$ and these 8 trials reported more than half the SAEs. The trials with overall low risk of bias reported the following SAEs: death, vein thrombosis, pneumonia, wound infection, admission to intensive care unit, and prolonged hospital stay.

\section{Trials with low risk of bias}

In the 0-350 mg subgroup, ${ }^{9,140}$ Peto's OR and TSA were not estimable. In the remaining subgroups, the risk of SAEs was: 351-700 mg subgroup: OR $0.9(0.2,3.4 ; p=0.85)^{9,76,107,128}$; $700-1050 \mathrm{mg}$ subgroup: OR $0.6(0.04,8.6 ; p=0.70)^{5}$; and $>1050$ mg subgroup: OR $2.0(0.9,4.5 ; p=0.1) .,{ }^{5,41,62}$ No subgroup differences were demonstrated for this outcome, and no systematic increase in SAEs was observed with increasing doses of gabapentin (Figure 4). It was only possible to conduct TSA on two subgroups (351-700 and $>1050 \mathrm{mg}$ ), and both subgroups had less than $20 \%$ of RIS and none reported firm evidence (Table 1).

\section{All trials}

None of the gabapentin subgroups demonstrated statistically significant increases in SAEs compared with controls (Figure 5). No significant differences between the different dose intervals were demonstrated, and no systematic increase in SAEs was observed with increasing doses of gabapentin (Table 2). TSA showed that none of the three subgroups, 351-700, 701-1050, and $>1050 \mathrm{mg}$, reached firm evidence, nor did they reach more than $5 \%$ of RIS.

\section{Secondary outcomes}

\section{Pain intensity}

Little data have been reported from trials with low risk of bias, limiting the reliability of the test for subgroup differences. No consistent dose-related trends or subgroup 


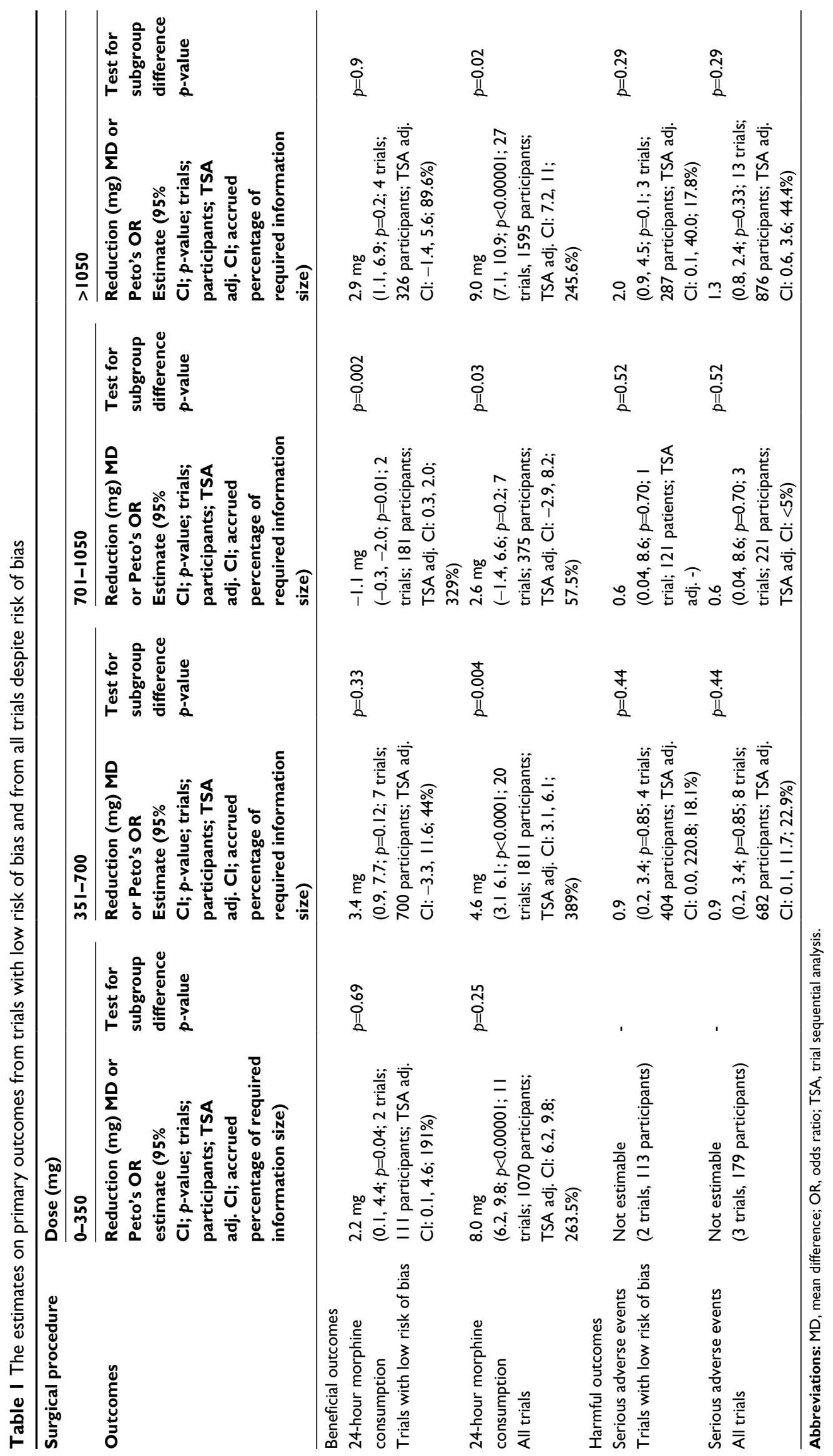




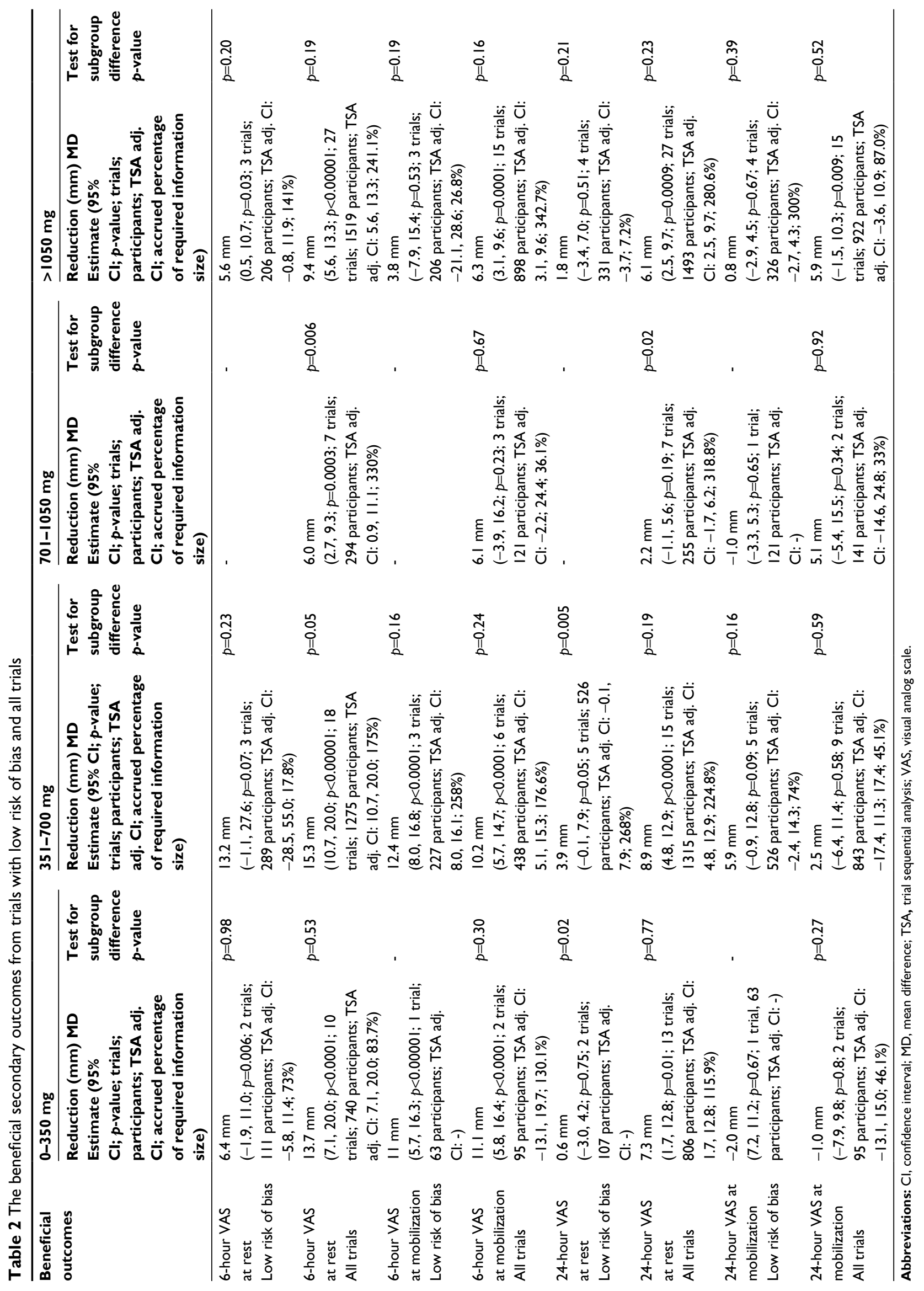


differences were demonstrated in the all trials estimates (Table 2; Supplementary material S5-S12: forest plots of pain intensities).

\section{Adverse events}

No consistent dose-related trends or subgroup differences were demonstrated either in data from trials with low risk of bias or in the all trials estimates (Table 3 ). None of the meta-analyses of trials with low risk of bias reporting risk of AE reached firm evidence according to TSA (Supplementary material S13-S20: forest plot of AE).

\section{Discussion}

In this review, we aimed to explore the effect of increasing doses of gabapentin on postoperative morphine consumption, SAEs, pain intensity, and adverse events in four groups of trials that included the most commonly used doses of gabapentin for perioperative pain management: 300, 600, 900, and $1200 \mathrm{mg}$.

For the primary beneficial outcome, 24-hour morphine consumption, no consistent increase in morphine-sparing effect was observed with increasing doses of gabapentin, either in the analysis of trials with low risk of bias or in the all trials analysis. On the contrary, the smallest (0-350 mg) and the largest $(>1050 \mathrm{mg}$ ) dose regimens demonstrated comparable and the most pronounced reduction in morphine consumption in the all trials analysis.

Only few SAEs were reported, limiting any reliable conclusion on this outcome. Of 72 stated SAEs, $83 \%$ were reported in the $>1050 \mathrm{mg}$ subgroup, indicating an increased risk of SAEs with increasing doses. Of the 27 trials reporting SAEs, 10 were classified as overall low risk of bias, and these 10 trials reported more than half the SAEs.

For the secondary outcomes, pain intensity and adverse events, no consistent dose-related trends or subgroup differences were demonstrated, either in data from trials with low risk of bias or in the all trials estimates.

We could not find any clear indication of a dose-related effect of gabapentin. A possible explanation may by the fact that higher doses of gabapentin lead to relatively smaller increases in blood concentrations because of the saturable absorption of gabapentin after oral administration. ${ }^{14,15,145}$ This may potentially provide an upper limit to the effect of beneficial outcomes and adverse events. However, none of our results indicated a clear upper limit or difference between subgroups, confirming this hypothesis. The nonlinear absorption may be the main reason of the less-predictable clinical effect of increased doses, but other explanations also have to be considered.

The analgesic effect of gabapentin is considered to be related to its antihyperalgesic properties, as demonstrated for both single and multiple dosing in human volunteer pain models. ${ }^{146,147}$ In such models, gabapentin did not affect nociceptive pain per se. ${ }^{146-148}$ Furthermore, gabapentin demonstrated dose-dependent antihyperalgesic effects in rat pain models, ${ }^{149}$ which, however, has not been investigated in humans. It is, therefore, unknown if increasing doses of gabapentin display increasing antihyperalgesic effects in humans, and if such a dose-response relationship is linear. This may contribute significantly to the shortcoming of detecting a dose-response effect in postoperative pain patients. Furthermore, postoperative pain is related to multiple pain mechanisms, of which hyperalgesia is only one. It is, though, unknown how important the hyperalgesic component is for the total sum of experienced pain. This may, in part, also explain the shortcomings of detecting a dose-response relationship for postoperative gabapentin treatment.

The optimal dose for postoperative pain treatment has been investigated in a few original clinical trials..$^{2-11,143}$ The study by Van Elstraete et al ${ }^{150}$ found a relatively high median effective analgesic dose of $21.7 \mathrm{mg} / \mathrm{kg}$ gabapentin in spinal fusion surgery. Considering this result, it is possible that the investigated doses, in general, are too low for analgesic efficacy, although higher doses (>1200 mg) most likely will produce profound adverse effects.

Most included trials were small in size, and $86 \%$ of the trials included less than 50 participants in each group, which can be a limitation. The large number of small-sized trials leads to repetitive testing in the cumulative meta-analyses, increasing the risk of random error. Accordingly, we applied TSA to compensate for this limitation. The majority of cumulative subgroup analyses of trials with low risk of bias did not reach firm evidence, or the RIS. This limits any firm evidence and conclusions. In addition, the lack of data may cause a type II error.

The strengths of these subgroup analyses are related to the primary systematic review that was carried out using Cochrane methodology and reported according to PRISMA guidelines. All trials were critically assessed using the Cochrane bias evaluation tools, and the risk of random error was assessed using TSA to adjust for sparse data and repetitive testing.

However, there are substantial limitations to our results. The conclusions based on our results are generally weakened 


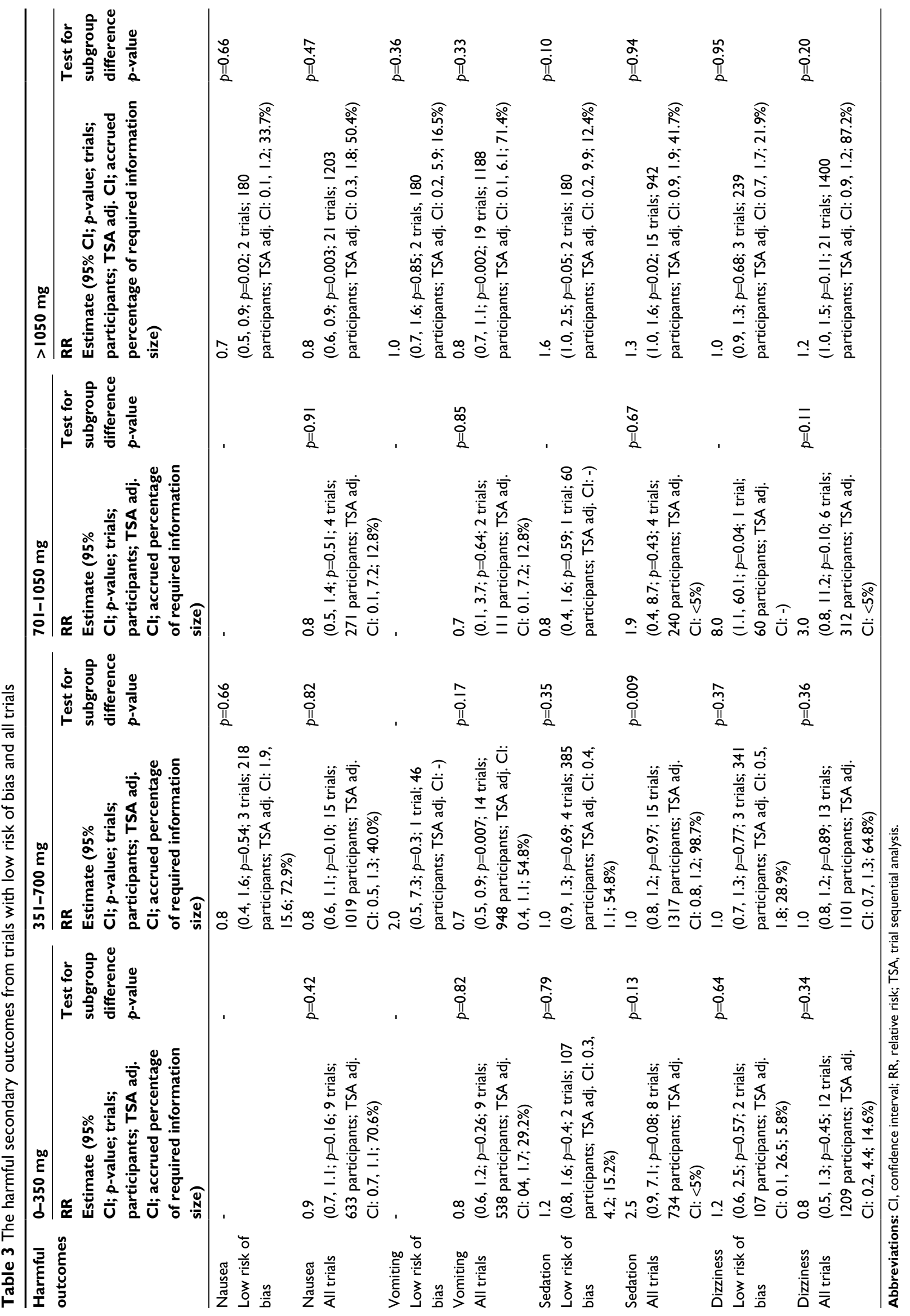




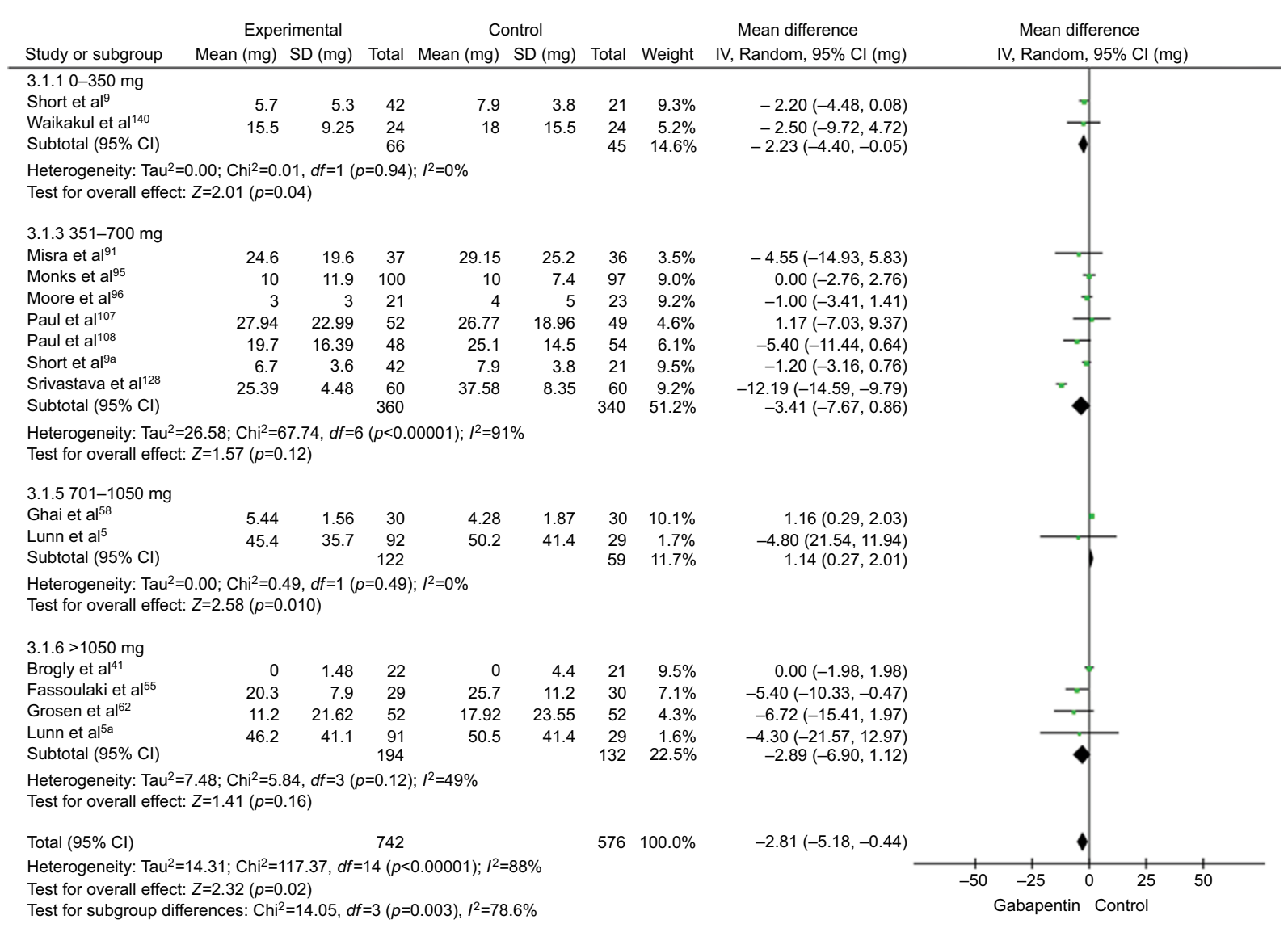

Figure 2 Forest plot of 24-hour morphine consumption from trials with overall low risk of bias.

Abbreviations: $d f$, degrees of freedom; $\mathrm{Cl}$, confidence interval; SD, standard deviation; IV, inverse variance.

by the low number of trials classified as overall low risk of bias, which limits the test for subgroup differences, and pooled estimates in meta-analyses. The few number of trials with low risk of bias means that all trials estimates must be factored into the evaluation and interpretation of these subgroup analyses. It is well described that estimates from trials with unclear and high risk of bias have an inherent risk of overestimating beneficial outcomes and underestimating harmful events, which must be taken into account upon conclusions and further use in future hypothesis based on these analyses. ${ }^{144}$

Few of the included trials reported SAEs, and most of the trials exhibited a short follow-up period, further limiting the analyses exploring the risks of gabapentin treatment. ${ }^{18}$

Further, this review consists of post hoc analyses, which limit the reliability of the results. The subgroups of our analyses must be interpreted as observational studies, with the inherent limitations of such studies: Confounding by other study characteristics may bias the analyses. Some of these study characteristics, such as gabapentin with other nonopioid analgesics, have been explored in the original work, ${ }^{18}$ while the effect of gabapentin in six different procedures was explored in a separate published article finding no difference between surgical procedures on beneficial and harmful outcomes from trials with overall low risk of bias. ${ }^{151}$

Our post hoc analysis was meant to explore the dose effect of gabapentin in published randomized clinical trials, since there is no previously published systematic on the topic. Based on the combined analyses, we cannot recommend a specific dose or regimen, if any, for perioperative gabapentin treatment. We hope that our analyses may inspire the hypotheses of future trials.

\section{Conclusion}

Data were sparse in all subgroups, and the small number of trials with low risk of bias is a major limitation for firm conclusions. Taking these limitations into account, we were not able to demonstrate a clear relationship between the dosage of gabapentin and opioid-sparing or harmful effects. Numerically, most SAEs were reported in the higher dosing groups, and trials with low risk of bias reported the most SAEs. These subgroup analyses are exploratory and hypothesis-generating for future trialists. 
Experimental

Control

Mean difference

Mean difference

Study or subgroup Mean $(\mathrm{mg}) \mathrm{SD}(\mathrm{mg})$ Total Mean $(\mathrm{mg}) \mathrm{SD}(\mathrm{mg})$ Total Weight $\quad \mathrm{IV}$, Random, $95 \% \mathrm{Cl}(\mathrm{mg}) \quad \mathrm{IV}, \mathrm{Random}, 95 \% \mathrm{Cl}(\mathrm{mg})$

\begin{tabular}{|c|c|c|c|c|c|c|c|c|}
\hline Amr et $\mathrm{al}^{30}$ & 13.5 & 0.5 & 50 & 22 & 2.1 & 50 & $2.1 \%$ & $-8.50(-9.10,-7.90)$ \\
\hline Bang et al ${ }^{34}$ & 32.07 & 29.07 & 23 & 30.07 & 28.57 & 23 & $0.5 \%$ & $2.00(-14.66,18.66)$ \\
\hline Clarke et al ${ }^{46}$ & 37 & 1.5 & 95 & 48 & 1.33 & 84 & $2.1 \%$ & $-11.00(-11.41,-10.59)$ \\
\hline Ghafari et al ${ }^{57}$ & 15.78 & 1.15 & 33 & 26.94 & 2.28 & 33 & $2.1 \%$ & $-11.16(-12.03,-10.29)$ \\
\hline Panday et al ${ }^{102}$ & 40.42 & 31.26 & 153 & 53.03 & 27.48 & 153 & $1.4 \%$ & $-12.61(-19.21,-6.01)$ \\
\hline Panday et al ${ }^{103}$ & 90.85 & 34.1 & 28 & 92.49 & 41.77 & 28 & $0.4 \%$ & $-1.64(-21.61,18.33)$ \\
\hline Sekhavet et al ${ }^{119}$ & 40.1 & 14.5 & 49 & 52.7 & 21.1 & 49 & $1.4 \%$ & $-12.60(-19.77,-5.43)$ \\
\hline Short et $\mathrm{al}^{9}$ & 5.7 & 5.3 & 42 & 7.9 & 3.8 & 21 & $2.0 \%$ & $-2.20(-4.48,0.08)$ \\
\hline Vahedi et al ${ }^{136}$ & 18.61 & 9.03 & 36 & 21.53 & 11.3 & 40 & $1.7 \%$ & $-2.92(-7.50,1.66)$ \\
\hline Waikakul et al ${ }^{140}$ & 15.5 & 9.25 & 24 & 18 & 15.5 & 24 & $1.4 \%$ & $-2.50(-9.72,4.72)$ \\
\hline Yoon et al ${ }^{141}$ & 24.1 & 9.9 & 16 & 32.7 & 14.6 & 16 & $1.2 \%$ & $-8.60(-17.24,0.04)$ \\
\hline Subtotal $(95 \% \mathrm{Cl})$ & & & 549 & & & 521 & $16.4 \%$ & $-8.02(-9.84,-6.19)$ \\
\hline
\end{tabular}

Heterogeneity: $\mathrm{Tau}^{2}=4.54 ; \mathrm{Chi}^{2}=114.81, d f=10(p<0.00001) ; l^{2}=91 \%$

Test for overall effect: $Z=8.61(p<0.00001)$

3.3.2 $351-700 \mathrm{mg}$

\begin{tabular}{|c|c|c|c|c|c|c|c|c|}
\hline Bharti et al ${ }^{40}$ & 2.1 & 2.2 & 20 & 4.9 & 3.4 & 20 & $2.1 \%$ & $-2.80(-4.57,-1.03)$ \\
\hline Clarke et $\mathrm{al}^{45}$ & 33.1 & 4 & 76 & 35 & 4 & 39 & $2.1 \%$ & $-1.90(-3.44,-0.36)$ \\
\hline Khademi et $\mathrm{al}^{71}$ & 2.83 & 1.29 & 44 & 3.51 & 1.51 & 43 & $2.1 \%$ & $-0.68(-1.27,-0.09)$ \\
\hline Maleh et $\mathrm{al}^{83}$ & 2.5 & 2.6 & 40 & 2.7 & 2.7 & 40 & $2.1 \%$ & $-0.20(-1.36,0.96)$ \\
\hline Mardani-Kivi et al ${ }^{85}$ & 2.5 & 2.3 & 55 & 3.7 & 2.5 & 53 & $2.1 \%$ & $-1.20(-2.11,-0.29)$ \\
\hline Menda et $a^{86}$ & 6 & 8.5 & 30 & 15.1 & 20 & 30 & $1.3 \%$ & $-9.10(-16.88,-1.32)$ \\
\hline Metry et al ${ }^{88}$ & 16.1 & 7.7 & 67 & 29.2 & 9.6 & 34 & $1.9 \%$ & $-13.10(-16.82,-9.38)$ \\
\hline Misra et al ${ }^{91}$ & 24.6 & 19.6 & 37 & 29.15 & 25.2 & 36 & $1.0 \%$ & $-4.55(-14.93,5.83)$ \\
\hline Monks et $\mathrm{al}^{95}$ & 10 & 11.9 & 100 & 10 & 7.4 & 97 & $2.0 \%$ & $0.00(-2.76,2.76)$ \\
\hline Moore et $\mathrm{al}^{96}$ & 3 & 3 & 21 & 4 & 5 & 23 & $2.0 \%$ & $-1.00(-3.41,1.41)$ \\
\hline Panday et al ${ }^{104}$ & 59.37 & 23.17 & 40 & 92.47 & 41.75 & 20 & $0.4 \%$ & $-33.10(-52.76,-13.44)$ \\
\hline Panday et al ${ }^{6}$ & 39.19 & 26.31 & 125 & 67.66 & 25.27 & 125 & $1.5 \%$ & $-28.47(-34-87,-22.07)$ \\
\hline Parikh et al ${ }^{105}$ & 31.7 & 20.3 & 30 & 31.9 & 19.84 & 30 & $1.0 \%$ & $-0.20(-10.36,9.96)$ \\
\hline Paul et al ${ }^{107}$ & 27.94 & 22.99 & 52 & 26.77 & 18.96 & 49 & $1.2 \%$ & $1.17(-7.03,9.37)$ \\
\hline Paul et al ${ }^{108}$ & 19.7 & 16.39 & 48 & 25.1 & 14.5 & 54 & $1.5 \%$ & $-5.40(11.44,0.64)$ \\
\hline Sava et al ${ }^{118}$ & 35.6 & 14.14 & 25 & 54.7 & 13.02 & 25 & $1.3 \%$ & $-19.10(-26.63,-11.57)$ \\
\hline Short et al ${ }^{9 a}$ & 6.7 & 3.6 & 42 & 7.9 & 3.8 & 21 & $2.0 \%$ & $-1.20(-3.16,0.76)$ \\
\hline Soltanzadeh et al ${ }^{126}$ & 2.5 & 0.9 & 30 & 4 & 1.5 & 30 & $2.1 \%$ & $-1.50(-2.13,0.87)$ \\
\hline Srivastava et al ${ }^{128}$ & 25.39 & 4.48 & 60 & 37.58 & 8.35 & 60 & $2.0 \%$ & $-12.19(-14.59,-9.79)$ \\
\hline Özcan et al ${ }^{99}$ & 15.3 & 5 & 20 & 19 & 4.2 & 20 & $2.0 \%$ & $-3.70(-6.56,-0.84)$ \\
\hline Subtotal $(95 \% \mathrm{Cl})$ & & & 962 & & & 849 & $33.7 \%$ & $-4.56(-6.08,-3.03)$ \\
\hline
\end{tabular}

Test for overall effect: $Z=5.87(p<0.00001)$

3.3.3 701-1050 mg

\begin{tabular}{|c|c|c|}
\hline Badawy et al ${ }^{32}$ & 11.5 & 2.3 \\
\hline Deniz et al ${ }^{47}$ & 22.2 & 11.9 \\
\hline Ghai et al ${ }^{58}$ & 5.44 & 1.56 \\
\hline Kim et $\mathrm{al}^{75}$ & 35.8 & 20.8 \\
\hline Lunn et $\mathrm{al}^{5}$ & 45.4 & 35.7 \\
\hline Marashi et al ${ }^{84}$ & 18.3 & 15.6 \\
\hline $\begin{array}{l}\text { Prabhakar et al }{ }^{109} \\
\text { Subtotal }(95 \% \mathrm{Cl})\end{array}$ & 23.8 & 5 \\
\hline
\end{tabular}

Subtotal $(95 \% \mathrm{Cl})$

Heterogeneity: $\mathrm{Tau}^{2}=16.88 ; \mathrm{Chi}^{2}=55.24, d f=6(p<0.00001) ; l^{2}=89 \%$

Test for overall effect: $Z=1.29(p=0.20)$

$3.3 .4>1050 \mathrm{mg}$

Abdelmageed et a

Al-Mujadi et al ${ }^{29}$

Bekawi et al ${ }^{38}$

Brogly et al ${ }^{41}$

Dierking et al

Doha et al $\left.\right|^{50}$

Durmus et al ${ }^{51}$

Fassoulaki et al ${ }^{53}$

Fassoulaki et al ${ }^{54}$

Frouzanfard et al ${ }^{56}$

Gilron et al60

Grosen et al ${ }^{62}$

Hout et al ${ }^{66}$

Joseph et al ${ }^{68}$

Khan et $\mathrm{al}^{72}$

Kosucu et al ${ }^{78}$

Lunn et al ${ }^{5} a$

Ménigaux et $\mathrm{al}^{87}$

Omran et $\mathrm{al}^{98}$

Sen et al ${ }^{121}$

Sen et al $^{122}$

Syal et al ${ }^{129}$

Turan et al ${ }^{12}$

Turan et al ${ }^{131}$

Ucak et al ${ }^{135}$

Ozgencil et al ${ }^{100}$

Subtotal $(95 \% \mathrm{Cl})$

$\begin{array}{rrr}6.6 & 1.3 & 3 \\ 15.2 & 7.6 & 35 \\ 0 & 2.2 & 30 \\ 0 & 1.48 & 22 \\ 43 & 23.7 & 40 \\ 39.9 & 33 & 30 \\ 40 & 10 & 25 \\ 23.8 & 5 & 2 \\ 20.3 & 7.9 & 29 \\ 22 & 2.9 & 30 \\ 1.2 & 0.29 & 25 \\ 56.78 & 32.41 & 23 \\ 11.2 & 21.62 & 52 \\ 2.36 & 2.5 & 23 \\ 38.65 & 18.04 & 25 \\ 13.21 & 4.71 & 34 \\ 25.9 & 8.3 & 29 \\ 46.2 & 41.1 & 91 \\ 21 & 12 & 20 \\ 23.9 & 2.6 & 25 \\ 31 & 12 & 20 \\ 20 & 11.5 & 30 \\ 40.2 & 35.2 & 30 \\ 27.04 & 14.44 & 25 \\ 16.3 & 8.9 & 25 \\ 9.9 & 5.38 & 20 \\ 29.47 & 9.64 & 30 \\ & & 823\end{array}$

$\begin{array}{rrrr}12.2 & 1.1 & 30 & 2.1 \% \\ 29.5 & 9 & 37 & 1.8 \% \\ 7.5 & 0.7 & 32 & 2.1 \% \\ 0 & 4.4 & 21 & 2.0 \% \\ 63 & 25.9 & 40 & 0.9 \% \\ 42.7 & 36.1 & 29 & 0.5 \% \\ 66 & 10 & 25 & 1.6 \% \\ 23.2 & 5.8 & 25 & 1.9 \% \\ 25.7 & 11.2 & 30 & 1.7 \% \\ 35 & 4.8 & 30 & 2.0 \% \\ 5.2 & 2.8 & 25 & 2.1 \% \\ 82.11 & 48.2 & 24 & 0.3 \% \\ 17.92 & 23.55 & 52 & 1.2 \% \\ 2.65 & 3.2 & 28 & 2.1 \% \\ 44.29 & 16.02 & 25 & 1.1 \% \\ 24.31 & 9.28 & 35 & 1.9 \% \\ 44 & 11 & 31 & 1.7 \% \\ 50.5 & 41.4 & 29 & 0.5 \% \\ 20 & 19 & 20 & 1.0 \% \\ 31.5 & 2.78 & 25 & 2.1 \% \\ 48 & 17 & 20 & 1.1 \% \\ 28 & 11.5 & 29 & 1.6 \% \\ 46.7 & 35.8 & 30 & 0.5 \% \\ 41.96 & 8.36 & 25 & 1.5 \% \\ 42.8 & 10.9 & 25 & 1.6 \% \\ 14.94 & 7.25 & 20 & 1.8 \% \\ 37.33 & 9.5 & 30 & 1.7 \% \\ & & 772 & 40.5 \%\end{array}$

$-5.60(-6.21,-4.99)$

$-5.60(-18.14,-10.46)$
$-7.50(-8.32,-6.68)$

$0.00(-1.98,1.98)$

$-20.00(-30.88,-9.12)$

$-2.80(-20.47,14.87)$

$-26.00(-31.54,-20.46)$

$0.60(-2.40,3.60)$

$-5.40(-10.33,-0.47)$

$-13.00(-15.01,-10.99)$

$-4.00(-5.10,-2.90)$

$-25.33(-48.72,-1.94)$

$-6.72(-15.41,1.97)$

$-0.29(-1.85,1.27)$

$-5.64(-15.10,3.82)$

$-11.10(-14.56,-7.64)$

$-18.10(-23.01,-13.19)$

$-4.30(-21.57,12.97)$

$1.00(-8.85,10.85)$

$-7.60(-9.09,-6.11)$

$-17.00(-26.12,-7.88)$

$-8.00(-13.87,-2.13)$

$-6.50(-24.47,11.47)$

$-14.92(-21.46,-8.38)$

$-26.50(-32.02,-20.98)$

$-5.04(-9.00,-1.08)$

$-7.86(-12.70,-3.02)$

$-8.98(-10.85,-7.10)$

Heterogeneity: Tau $^{2}=15.95 ; \mathrm{Chi}^{2}=360.74, d f=26(p<0.00001) ; I^{2}=93 \%$

Test for overall effect: $Z=9.38(p<0.00001)$

Total $(95 \% \mathrm{Cl})$

Heterogeneity: $\mathrm{Tau}^{2}=23.83 ; \mathrm{Chi}^{2}=2408.40, d f=64(p<0.00001) ; I^{2}=97 \%$ Test for overall effect: $Z=9.90(p<0.00001)$

Test for subgroup differences: $\mathrm{Chi}^{2}=19.30 \mathrm{df}=3(p=0.002), I^{2}=84.5 \%$

$2298 \quad 100.0 \%$

$-7.06(-8.46,-5.66)$

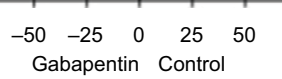

Figure 3 Forest plot of 24-hour morphine consumption from all trials estimates regardless of bias evaluation.

Abbreviations: $d f$, degrees of freedom; $\mathrm{Cl}$, confidence interval; SD, standard deviation; IV, inverse variance. 


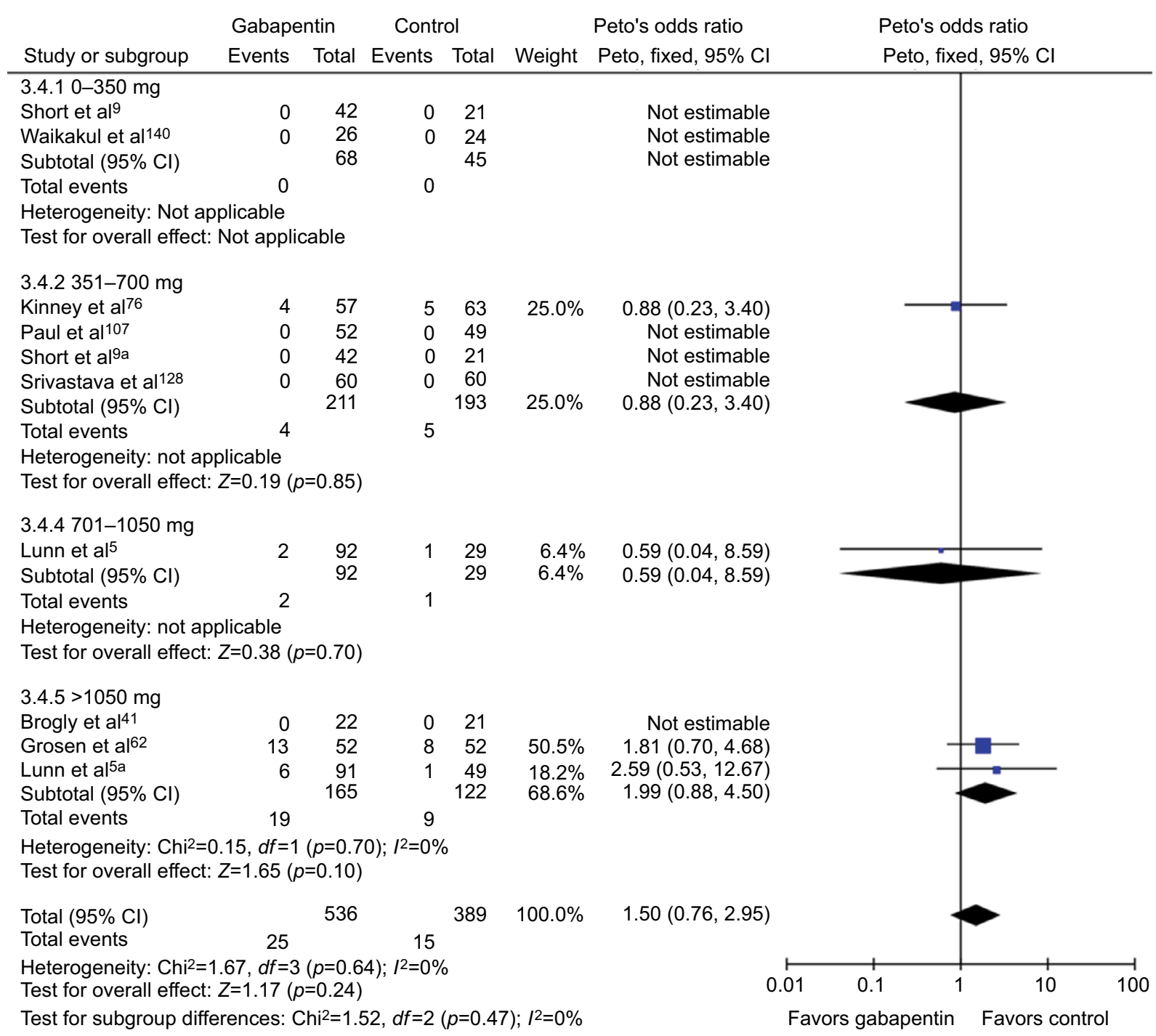

Figure 4 Forest plot of the odds of serious adverse events from trials with overall low risk of bias. Abbreviations: $d f$, degrees of freedom; $\mathrm{Cl}$, confidence interval.

\section{Acknowledgments}

These are post hoc subgroup analyses from a systematic review with meta-analyses and trial sequential analyses: Fabritius ML, Geisler A, Hansen MS, Nikolajsen L, Hamunen K, Kontinen V, Wetterslev J, Dahl JB, Mathiesen O. Gabapentin for post-operative pain management - a systematic review with meta-analyses and trial sequential analyses. Acta Anaesthesiol Scand. 2016;60:1188-1208.

We would like to thank Sarah Louise Klingenberg, Trial Search Coordinator at Cochrane Hepato-Biliary Group for the extensive literature searches; and Morten Sejer Hansen, MD, Department of Anaesthesiology, Centre of Head and Orthopaedics, Rigshospitalet, Copenhagen University Hospital, Denmark; Lone Nikolajsen, DMSci, Professor,
Department of Anaesthesiology, Aarhus University Hospital, Denmark; Anja Geisler, RN, Department of Anaesthesiology, Zealand University Hospital, Køge, Denmark; and Pernille Lykke Petersen, MD, PhD, Department of Anaesthesiology, Centre of Head and Orthopaedics, Copenhagen University Hospital, Rigshospitalet, Denmark, for their help in data extraction.

The project was supported by departmental funding from the Department of Anaesthesiology, Centre of Head and Orthopaedics, Copenhagen University Hospital, Rigshospitalet, Department of Anaesthesiology, Bispebjerg and Frederiksberg Hospitals and Copenhagen Trial Unit, Centre for Clinical Intervention Research, Copenhagen University Hospital, Rigshospitalet. 


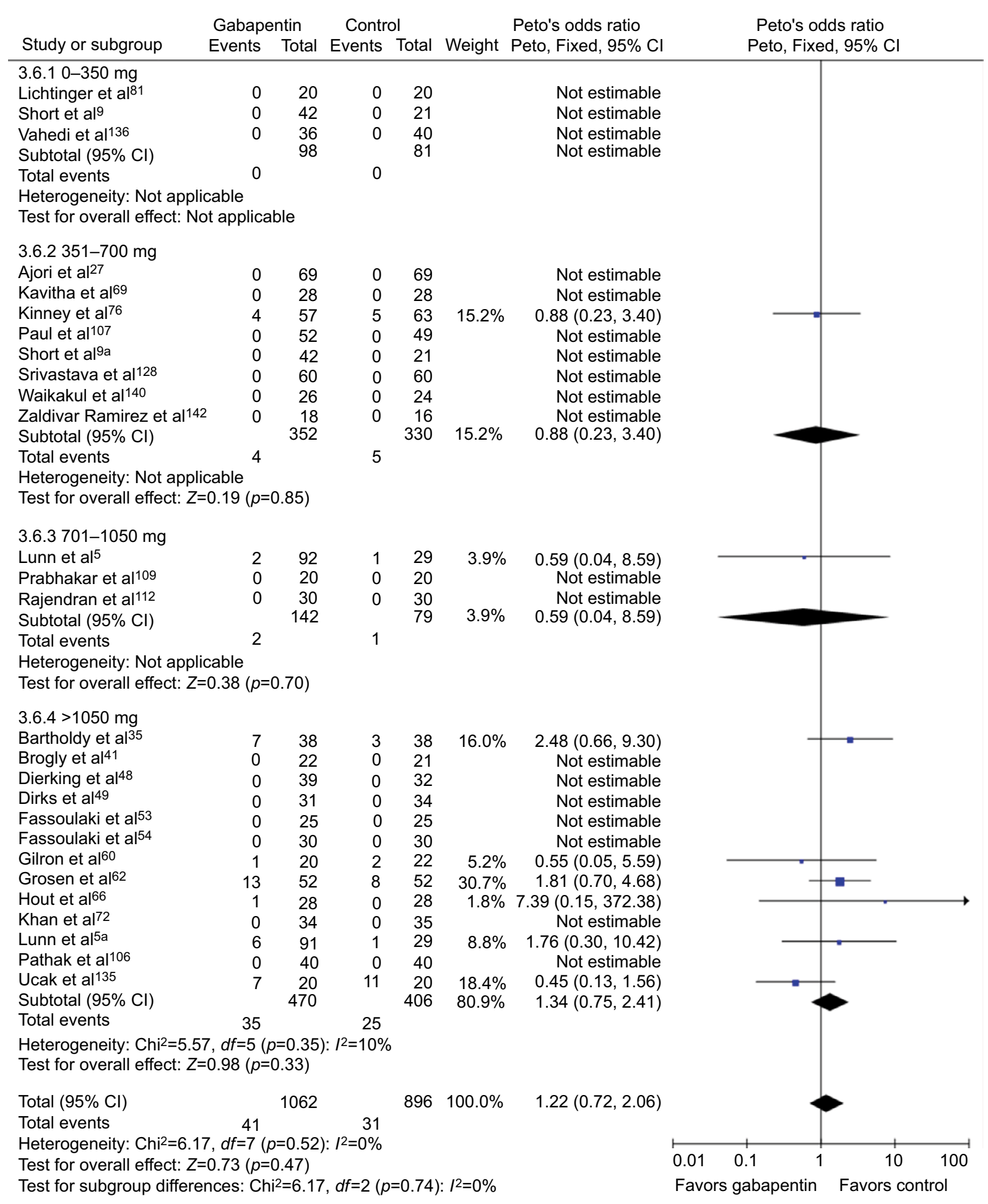

Figure 5 Forest plot of the odds of serious adverse events from all trials estimates, regardless of bias evaluation. Abbreviation: $d f$, degrees of freedom.

\section{Author contributions}

All authors meet the criteria, ICMJE recommendations for authorship and have made substantial contributions to conception and design, acquisition of data, or analysis and interpretation of data, have revised the article critically for important intellectual content, and have given their final approval of the version to be published. All authors have agreed to be accountable for all aspects of the work. 


\section{Disclosure}

The authors report no conflicts of interest in this work.

\section{References}

1. Clarke H, Pereira S, Kennedy D, et al. Gabapentin decreases morphine consumption and improves functional recovery following total knee arthroplasty. Pain Res Manag. 2009;14(3):217-222.

2. Erten E, Bilgin F, Çekmen N, et al. The analgesic effect of different doses of preemptive gabapentin preoperatively on patients undergoing elective laminectomy during postoperative period [Elektif laminektomi operasyonu gecirecek hastalarda preoperatif verilen gabapentinin farkli dozlarinin postoperatif analjeziye etkisi]. Anestzi Dergisi 2010;18:99-105.

3. Khan ZH, Rahimi M, Makarem J, et al. Optimal dose of pre-incision/ post-incision gabapentin for pain relief following lumbar laminectomy: a randomized study. Acta Anaesthesiol Scand. 2011;55(3):306-312.

4. Kumar A. Effect of single dose gabapentin on postoperative pain and opioid consumption following total abdominal hysterectomy: a Dose Finding Study. International Conference on Surgery and Anesthesia Atlanta. USA Br J Anaesth. 2012;108:2019.

5. Lunn TH, Husted H, Laursen MB, et al. Analgesic and sedative effects of perioperative gabapentin in total knee arthroplasty: a randomized, double-blind, placebo-controlled dose-finding study. Pain. 2015;156(12):2438-2448.

6. Pandey CK, Navkar DV, Giri PJ, et al. Evaluation of the optimal preemptive dose of gabapentin for postoperative pain relief after lumbar diskectomy: a randomized, double-blind, placebo-controlled study. J Neurosurg Anesthesiol. 2005;17(2):65-68.

7. Raghove P, Jaiswal R, Singh K. Evaluating the effect of preoperative oral gabapentin on postoperative pain in patients receiving spinal anaesthesia for lower limb surgery. South Afr J Anaesthesiol Analg. 2010;16(6):9-12.

8. Said-Ahmed HAF. Dose ranging study of gabapentin for postoperative pain after myomectomy [Studio de diversi dosaggi de gabapentin nel trattamento del dolore postoperatorio dopo miomectomia].Acta Anaest Italica 2007;58(1):23-34.

9. Short J, Downey K, Bernstein P, et al. A single preoperative dose of gabapentin does not improve postcesarean delivery pain management: a randomized, double-blind, placebo-controlled dose-finding trial. Anesth Analg. 2012;115(6):1336-1342.

10. Takmaz SA, Kaymak C, Pehlivan BS, et al. [Effect of preoperative 900 and $1200 \mathrm{mg}$ single oral dose of gabapentin on postoperative pain relief and tramadol consumption in open cholecystectomy surgery]. Agri. 2007;19(3):32-38.

11. Tuncer S, Bariskaner H, Reisli R, et al. Effect of gabapentin on postoperative pain: a randomized, placebo-controlled clinical study. The Pain Clinic. 2013;17(1):95-99.

12. Turan A, Karamanlioglu B, Memis D, Usar P, Pamukcu Z, Ture M. The analgesic effects of gabapentin after total abdominal hysterectomy. Anesth Analg. 2004;98(5):1370-1373.

13. McLean MJ. Clinical pharmacokinetics of gabapentin. Neurology. 1994;44(6 Supp1 5):S17-S22; discussion S31-S32.

14. Bockbrader HN, Wesche D, Miller R, Chapel S, Janiczek N, Burger P. A comparison of the pharmacokinetics and pharmacodynamics of pregabalin and gabapentin. Clin Pharmacokinet. 2010;49(10):661-669.

15. Chen C. Meta-analyses of dose-exposure relationships for gabapentin following oral administration of gabapentin and gabapentin enacarbil. Eur J Clin Pharmacol. 2013;69(10):1809-1817.

16. Vollmer KO, Anhut H, Thomann P, et al. Pharmacokinetic model and absolute bioavailability of the new anticonvulsant gabapentin. $A d v$ Epileptol. 1989;17:209-211.

17. Fabritius ML, Geisler A, Hansen MS, et al. Benefit and harm of perioperative gabapentin treatment: a systematic review of randomised clinical trials with meta-analyses and trial sequential analyses. PROSPERO. 2013.
18. Fabritius ML, Geisler A, Petersen PL, et al. Gabapentin for post-operative pain management - a systematic review with meta-analyses and trial sequential analyses. Acta Anaesth Scand. 2016;60(9):1188-1208.

19. Farzi F, Haddadi S, Ebrahimpour N, et al. A survey of the effect of oral gabapentin on hemodynamic changes during direct laryngoscopy and trachal intubation and intraoperative bleeding in patients undergoing septorhinoplasty. Anesth Pain Med. 2015;5(5):e29705.

20. Higgins JP, Altman DG, Gotzsche PC, et al. The Cochrane Collaboration's tool for assessing risk of bias in randomised trials. $B M J$. 2011;343:d5928.

21. Nickerson RS. Confirmation bias: a ubiquitous phenomenon in many guises. Rev Gen Psychol. 1998;2(2):175-220.

22. Deeks JJ, Higgins JPT, Altman DG. Chapter 9: Analysing data and undertaking meta-analyses. In: Higgins JPT, Green S, editors. Cochrane Handbook for Systematic Reviews of Interventions. Chichester, UK: Wiley; 2008.

23. Thorlund K, Imberger G, Walsh M, et al. The number of patients and events required to limit the risk of overestimation of intervention effects in meta-analysis-a simulation study. PLoS One. 2011;6(10):e25491.

24. Wetterslev J, Thorlund K, Brok J, Gluud C. Estimating required information size by quantifying diversity in random-effects model meta-analyses. BMC Med Res Methodol. 2009;9(1):86.

25. Pandey CK, Priye S, Singh S, Singh U, Singh RB, Singh PK. Preemptive use of gabapentin significantly decreases postoperative pain and rescue analgesic requirements in laparoscopic cholecystectomy. Can J Anaesth. 2004;51(4):358-363.

26. Abdelmageed WM, Abdelrazik S, Nassar A, et al. Analgesic effects of gabapentin in tonsillectomy. EJHM. 2010;38:51-58.

27. Adam F, Menigaux C, Sessler DI, Chauvin M. A single preoperative dose of gabapentin (800 milligrams) does not augment postoperative analgesia in patients given interscalene brachial plexus blocks for arthroscopic shoulder surgery. Anesth Analg. 2006;103(5):1278-1282.

28. Ajori L, Nazari L, Mazloomfard MM, Amiri Z. Effects of gabapentin on postoperative pain, nausea and vomiting after abdominal hysterectomy: a double blind randomized clinical trial. Arch Gynecol Obstet. 2012;285(3):677-682.

29. Al-Mujadi H, A-Refai AR, Katzarov MG, et al. Preemptive gabapentin reduces postoperative pain and opioid demand following thyroid surgery. Can J Anaesth. 2006;53(3):268-273.

30. Amr YM, Yousef AA. Evaluation of efficacy of the perioperative administration of Venlafaxine or gabapentin on acute and chronic postmastectomy pain. Clin J Pain. 2010;26(5):381-385.

31. Azemati S, Dokouhaki AG, Talei A, et al. Evaluation of the effect of a preoperative single dose of gabapentin on emergence agitation in patients undergoing breast cancer surgery. Middle East J Cancer. 2013;4(4):145-151.

32. Badawy AA, Sakka AE. Preoperative gabapentin alone or in combination with dexamethasone on postoperative pain relief after abdominal hysterectomies. A randomized controlled trial. Eg J Anaesth. 2015;31(2):107-113.

33. Bakry AEAE, Marey H. The effect of gabapentin premedication on pain and anxiety during cataract surgery under peribulbar block. Eg J Anaesth. 2012;28(1):43-47.

34. Bang SR, Yu SK, Kim TH. Can gabapentin help reduce postoperative pain in arthroscopic rotator cuff repair? A prospective, randomized, double-blind study. Arthroscopy. 2010;26(9 Suppl):S106-S111.

35. Bartholdy J, Hilsted KL, Hjortsoe NC, Engbaek J, Dahl JB. Effect of Gabapentin on morphine demand and pain after laparoscopic sterilization using Filshie clips. A double blind randomized clinical trial. $B M C$ Anesthesiol. 2006;6(1):12.

36. Bashir F, Mohd K, Qazi S, Hashia AM. A randomized, double blind, placebo controlled study evaluating preventive role of gabapentin for PONV in patients undergoing laparoscopic cholecystectomy. JK Science 2009;11:190-193.

37. Behdad S, Ayatollahi V, Bafghi AT, Tezerjani MD, Abrishamkar M. Effect of gabapentin on postoperative pain and operation complications: a randomized placebo controlled trial. West Indian Med J. 2012;61(2):128-133. 
38. Bekawi MS, El Wakeel LM, Al Taher WM, Mageed WM. Clinical study evaluating pregabalin efficacy and tolerability for pain management in patients undergoing laparoscopic cholecystectomy. Clin J Pain. 2014;30(11):944-952.

39. Bhandari V, Dhasmana D, Sharma J, Sachan P, Chaturvedi A, Dureja S. Gabapentin for post-operative nausea and vomiting: a pilot study. Int J Basic Clin Pharmacol. 2014;3(4):627.

40. Bharti N, Bala I, Narayan V, Singh G. Effect of gabapentin pretreatment on propofol consumption, hemodynamic variables, and postoperative pain relief in breast cancer surgery. Acta Anaesthesiol Taiwan. 2013;51(1):10-13.

41. Brogly N, Wattier JM, Andrieu G, et al. Gabapentin attenuates late but not early postoperative pain after thyroidectomy with superficial cervical plexus block. Anesth Analg. 2008;107(5):1720-1725.

42. Butt A, Mohammad K, Ommid M, Ahmad M, Jehan N, Qazi S. A randomized double blind placebo controlled study of prophylactic gabapentin for prevention of postoperative pain and morphine consumption in patients undergoing mastectomy. Internet $J$ Anesthesiol. 2010;30:1.

43. Celebi T, Kocamanoğlu I, Üstün YB, Sahinglu H. The effects of preemptive ketamine and gabapentin on volatile agent consumption, postoperative analgesic requirements and chronic pain [Preemptif uygulanan ketamin ve gabapentinin volatil ajan tüketimine, postoperatif analjezi gereksinimine ve kronik agriya etkileri]. TurkJ Anaesth Reanim. 2013;41(2):38-43.

44. Chowdhury L, Chakraborty S, Chakrabarti J, et al. Analgesic effect of low dose gabapentin in day-case gynaecological surgery under general anaesthesia. J Indian Med Assoc. 2010;108(11):734-771.

45. Clarke H, Kirkham KR, Orser BA, et al. Gabapentin reduces preoperative anxiety and pain catastrophizing in highly anxious patients prior to major surgery: a blinded randomized placebo-controlled trial. Can J Anaesth. 2013;60(5):432-443.

46. Clarke HA, Katz J, McCartney CJ, et al. Perioperative gabapentin reduces $24 \mathrm{~h}$ opioid consumption and improves in-hospital rehabilitation but not post-discharge outcomes after total knee arthroplasty with peripheral nerve block. Brit J Anaesth. 2014;113(5):855-864.

47. Deniz MN, Sertoz N, Erhan E, Ugur G. Effects of preoperative gabapentin on postoperative pain after radical retropubic prostatectomy. J Int Med Res. 2012;40(6):2362-2369.

48. Dierking G, Duedahl TH, Rasmussen ML, et al. Effects of gabapentin on postoperative morphine consumption and pain after abdominal hysterectomy: a randomized, double-blind trial. Acta Anaesth Scand. 2004; 48(3):322-327.

49. Dirks J, Fredensborg BB, Christensen D, Fomsgaard JS, Flyger H, Dahl JB. A randomized study of the effects of single-dose gabapentin versus placebo on postoperative pain and morphine consumption after mastectomy. Anesthesiology. 2002;97(3):560-564.

50. Doha NM, Rady A, El Azab SR. Preoperative use of gabapentin decreases the anesthetic and analgesic requirements in patients undergoing radical mastectomy. Eg J Anaesth. 2010;26(4):287-291.

51. Durmus M, Kadir But A, Saricicek V, Ilksen Toprak H, Ozcan Ersoy M. The post-operative analgesic effects of a combination of gabapentin and paracetamol in patients undergoing abdominal hysterectomy: a randomized clinical trial. Acta Anaesth Scand. 2007;51(3):299-304.

52. Ercan S, Akpek E, Aslim E, Akay T, Donmez A. The effects of gabapentin on intraoperative cooperation, stress response and postoperative analgesia in patients undergoing carotid endartectomy with regional anesthesia. J Cardiovasc Thoracic Anaesth Intensive Care Soc. 2014;20(1):7-15.

53. Fassoulaki A, Melemeni A, Stamatakis E, Petropoulos G, Sarantopoulos C. A combination of gabapentin and local anaesthetics attenuates acute and late pain after abdominal hysterectomy. Eur J Anaesthesiol. 2007;24(6):521-528

54. Fassoulaki A, Patris K, Sarantopoulos C, Hogan Q. The analgesic effect of gabapentin and mexiletine after breast surgery for cancer. Anesth Analg. 2002;95(4):985-991, table of contents.
55. Fassoulaki A, Stamatakis E, Petropoulos G, Siafaka I, Hassiakos D, Sarantopoulos C. Gabapentin attenuates late but not acute pain after abdominal hysterectomy. Eur J Anaesthesiol. 2006;23(2):136-141.

56. Frouzanfard F, Fazel MR, Abolhasani A, Fakharian E, Mousavi G, Moravveji A. Effects of gabapentin on pain and opioid consumption after abdominal hysterectomy. Pain Res Manag. 2013;18(2):94-96.

57. Ghafari MH, Akrami M, Nouralishahi B, et al. Preoperative gabapentin or clonidine decreases postoperative pain and morphine consumption after abdominal hysterectomy. Res J Biol Sci. 2009;4(4):458-463.

58. Ghai A, Gupta M, Hooda S, Singla D, Wadhera R. A randomized controlled trial to compare pregabalin with gabapentin for postoperative pain in abdominal hysterectomy. Saudi J Anaesth. 2011;5(3):252-257.

59. Ghai A, Gupta M, Rana N, et al. The effect of pregabalin and gabapentin on preoperative anxiety and sedation: a double blind study. Anaesth Pain Intensive Care. 2012;3:257-261.

60. Gilron I, Orr E, Tu D, O’Neill JP, Zamora JE, Bell AC. A placebocontrolled randomized clinical trial of perioperative administration of gabapentin, rofecoxib and their combination for spontaneous and movement-evoked pain after abdominal hysterectomy. Pain. 2005;113(1-2):191-200.

61. Gosai N, Patel L, Patel D, Umarania R, Patel B. Comparative evaluation of gabapentin and clonidine for premedication on postoperative analgesia in patient undergoing modified radical mastectomy under general anesthesia. Asain Pac J Health Sci. 2015;2(2):59-63.

62. Grosen K, Drewes AM, Hojsgaard A, Pfeiffer-Jensen M, Hjortdal VE, Pilegaard HK. Perioperative gabapentin for the prevention of persistent pain after thoracotomy: a randomized controlled trial. Eur J Cardiothorac Surg. 2014;46(1):76-85.

63. Grover VK, Mathew PJ, Yaddanapudi S, Sehgal S. A single dose of preoperative gabapentin for pain reduction and requirement of morphine after total mastectomy and axillary dissection: randomized placebocontrolled double-blind trial. J Postgrad Med. 2009;55(4):257-260.

64. Hassani V, Pazouki A, Nikoubakht N, Chaichian S, Sayarifard A, Shakib Khankandi A. The effect of gabapentin on reducing pain after laparoscopic gastric bypass surgery in patients with morbid obesity: a randomized clinical trial. Anesth Pain Med. 2015;5(1):e22372.

65. Hoseini VS, Yekta R, Marashi S, Marashi SM. The efficacy of melatonin, clonidine and gabapentin in reducing preoperative anxiety and postoperative pain in patients undergoing laparoscopic cholecystectomy: a randomized clinical trial. Archiv Anesthesiol Crit Care. 2015;1(4):120-125.

66. Huot MP, Chouinard P, Girard F, et al. Gabapentin does not reduces post-thoracotomy shoulder pain: a randomized, double-blind placebocontrolled study [La gabapentine ne réduit pas la douleur à l'épaule post-thoracotomie: une étude randomisée, à double insu et contrôlée par placebo]. Can J Anesth. 2008;55(6):337-343.

67. Jadeja C, Kathiria M, Jadaliwala R. Pre-emptive use of gabapentin for post-operative pain relief in upper abdominal surgeries. Indian $J$ Pain. 2014;28(2):99.

68. Joseph TT, Krishna HM, Kamath S. Premedication with gabapentin, alprazolam or a placebo for abdominal hysterectomy: effect on preoperative anxiety, post-operative pain and morphine consumption. Indian J Anaesth. 2014;58(6):693-699.

69. Kavitha J, Parida S, Kundra P, Srinivasan R. Oral gabapentin premedication for elderly patients undergoing intraocular surgery. $\mathrm{Br} J$ Ophthalmol. 2013;97(7):900-904.

70. Kazak Z, Meltem Mortimer N, Sekerci S. Single dose of preoperative analgesia with gabapentin $(600 \mathrm{mg})$ is safe and effective in monitored anesthesia care for nasal surgery. Eur Arch Otorhinolaryngol. 2010;267(5):731-736

71. Khademi S, Ghaffarpasand F, Heiran HR, Asefi A. Effects of preoperative gabapentin on postoperative nausea and vomiting after open cholecystectomy: a prospective randomized double-blind placebocontrolled study. Med Princ Pract. 2010;19(1):57-60.

72. Khan MA, Siddiqi KJ, Aqeel M. Effect of gabapentin on opioid requirements in patients undergoing total abdominal hysterectomy. Anaesth Pain Intensive Care. 2013;17(2):131-135. 
73. Khezri MB, Oladi MR, Atlasbaf A. Effect of melatonin and gabapentin on anxiety and pain associated with retrobulbar eye block for cataract surgery: a randomized double-blind study. Indian J Pharmacol. 2013;45(6):581-586.

74. Khurana G, Jindal P, Sharma JP, Bansal KK. Postoperative pain and long-term functional outcome after administration of gabapentin and pregabalin in patients undergoing spinal surgery. Spine (Phila $\mathrm{Pa}$ 1976). 2014;39(6):E363-E368.

75. Kim SI, Dash SK, Ok SY, et al. Effect of pre-emptive gabapentin on postoerative pain after mastectomy. Korean J Anesthesiol 2004;47(4):527-531.

76. Kinney MA, Mantilla CB, Carns PE, et al. Preoperative gabapentin for acute post-thoracotomy analgesia: a randomized, double-blinded, active placebo-controlled study. Pain Pract. 2012;12(3):175-183.

77. Koc S, Memis D, Sut N. The preoperative use of gabapentin, dexamethasone, and their combination in varicocele surgery: a randomized controlled trial. Anesth Analg. 2007;105(4):1137-1142, table of contents.

78. Koşucu M. The effects of the pre-emptive oral gabapentin on postanesthesia recovery criteria, acute post-thoracotomy pain and development of chronicity in pain with benign thoracotomy operations. Turk Gogus Kalp Dama. 2014;22(2):389-396.

79. Kuhnle MD, Ryan DS, Coe CD, et al. Oral gabapentin for photorefractive keratectomy pain. J Cataract Refract Surg. 2011;37(2): 364-369.

80. Leung JM, Sands LP, Rico M, et al. Pilot clinical trial of gabapentin to decrease postoperative delirium in older patients. Neurology. 2006;67(7):1251-1253

81. Lichtinger A, Purcell TL, Schanzlin DJ, Chayet AS. Gabapentin for postoperative pain after photorefractive keratectomy: a prospective, randomized, double-blind, placebo-controlled trial. J Refract Surg. 2011;27(8):613-617.

82. Mahoori A, Noroozinia H, Hasani E, Hosainzadeh S. The effect of pre-operative administration of gabapentin on post-operative pain relief after herniorrhaphy. Saudi J Anaesth. 2014;8(2):220-223.

83. Maleh PA, Alijanpour E, Nickbakhsh N, et al. Effects of gabapentin on postoperative pain following laparoscopic cholecystectomy. J Mazand Univ Med Sci. 2013;23(103):28-31.

84. Marashi SM, Morabi AA. The effect of pre-operative oral clonidine or gabapentin on post-operative pain intensity, morphine consumption and post-operative nausea and vomiting in patients who undergone thyroidectomy: a double-blind placebo-control study. J Anesth Clin Res. 2012;3(4):2-4.

85. Mardani-Kivi M, Mobarakeh MK, Keyhani S, Motlagh KH, Ekhtiari $\mathrm{KS}$. Is gabapentin effective on pain management after arthroscopic anterior cruciate ligament reconstruction? A triple blinded randomized controlled trial. Arch Bone Jt Surg. 2013;1(1):18-22.

86. Menda F, Koner O, Sayin M, Ergenoglu M, Kucukaksu S, Aykac B. Effects of single-dose gabapentin on postoperative pain and morphine consumption after cardiac surgery. J Cardiothorac Vasc Anesth. 2010;24(5):808-813.

87. Menigaux C, Adam F, Guignard B, Sessler DI, Chauvin M. Preoperative gabapentin decreases anxiety and improves early functional recovery from knee surgery. Anesth Analg. 2005;100(5):1394-1399, table of contents.

88. Metry A, Ishak S, Khattab A. Does gabapentin have preemptive effects in women undergoing mastectomy? [Il gabapentin possiede un effetto pre-emptive in pazienti sottoposte a mastectomia?]. Acta Anaesth Italica. 2008;59(1):62-76.

89. Mikkelsen S, Hilsted KL, Andersen PJ, et al. The effect of gabapentin on post-operative pain following tonsillectomy in adults. Acta Anaesth Scand. 2006;50(7):809-815.

90. Mishra R, Tripathi M, Chandola HC. Comparative clinical study of gabapentin and pregabalin for postoperative analgesia in laparoscopic cholecystectomy. Anesth Essays Res. 2016;10(2):201-206.
91. Misra S, Parthasarathi G, Vilanilam GC. The effect of gabapentin premedication on postoperative nausea, vomiting, and pain in patients on preoperative dexamethasone undergoing craniotomy for intracranial tumors. J Neurosurg Anesthesiol. 2013;25(4):386-391.

92. Mohammadi SS, Seyedi M. Comparing oral gabapentin versus clonidine as premedication on early postoperative pain, nausea and vomiting following general anesthesia. Saudi J Anaesth. 2009;3(1):25-28.

93. Mohammadi SS, Seyedi M. Effects of gabapentin on early postoperative pain, nausea and vomiting in laparoscopic surgery for assisted reproductive technologies. Pak J Biol Sci. 2008;11(14):1878-1880.

94. Mohammed MH, Fahmy AM, Hakim KYK. Preoperative gabapentin augments intraoperative hypotension and reduces postoperative opioid requirements with functional endoscopic sinus surgery. Eg J Anaesth. 2012;28(3):189-192

95. Monks DT, Hoppe DW, Downey K, Shah V, Bernstein P, Carvalho JC. A Perioperative course of gabapentin does not produce a clinically meaningful improvement in analgesia after cesarean delivery: a randomized controlled trial. Anesthesiology. 2015;123(2): 320-326

96. Moore A, Costello J, Wieczorek P, Shah V, Taddio A, Carvalho JC. Gabapentin improves postcesarean delivery pain management: a randomized, placebo-controlled trial. Anesth Analg. 2011;112(1):167-173.

97. Neogi M, Basak S, Ghosh D, Mukherjee S, Dawn S, Bhattacharjee DP. A randomized double-blind placebo-controlled clinical study on the effects of gabapentin premedication on hemodynamic stability during laparoscopic cholecystectomy. JAnaesthesiol Clin Pharmacol. 2012;28(4):456-459.

98. Omran AF, Mohammed AE. A randomized study of the effects of gabapentin versus placebo on post-thoracotomy pain and pulmonary function. Eg J Anaesth. 2005;21:277-281.

99. Ozcan B, Turgut N, Altan A, Ali A, Kaya M. Preemptive gabapentin in patients undergoing surgery for supratentorial tumour. Med $J$ Okmeydanı Training Res Hosp. 2012;28(3):126-133.

100. Ozgencil E, Yalcin S, Tuna H, Yorukoglu D, Kecik Y. Perioperative administration of gabapentin 1,200 $\mathrm{mg}$ day $(-1)$ and pregabalin 300 $\mathrm{mg}$ day $(-1)$ for pain following lumbar laminectomy and discectomy: a randomised, double-blinded, placebo-controlled study. Singap Med J. 2011;52(12):883-889.

101. Pakravan M, Roshani M, Yazdani S, Faramazi A, Yaseri M. Pregabalin and gabapentin for post-photorefractive keratectomy pain: a randomized controlled trial. Eur J Ophthalmol. 2012;22(Suppl 7):S106-S113.

102. Pandey CK, Priye S, Ambesh SP, Singh S, Singh U, Singh PK. Prophylactic gabapentin for prevention of postoperative nausea and vomiting in patients undergoing laparoscopic cholecystectomy: a randomized, double-blind, placebo-controlled study. J Postgrad Med. 2006;52(2):97-100.

103. Pandey CK, Sahay S, Gupta D, et al. Preemptive gabapentin decreases postoperative pain after lumbar discoidectomy. Can J Anaesth. 2004;51(10):986-989.

104. Pandey CK, Singhal V, Kumar M, et al. Gabapentin provides effective postoperative analgesia whether administered pre-emptively or postincision. Can J Anaesth. 2005;52(8):827-831.

105. Parikh HG, Dash SK, Upasani CB. Study of the effect of oral gabapentin used as preemptive analgesia to attenuate post-operative pain in patients undergoing abdominal surgery under general anesthesia. Saudi J Anaesth. 2010;4(3):137-141

106. Pathak L, Chaturvedi AS. Effect of gabapentin premedication on preoperative anxiety and postoperative pain. Health Renaissance. 2013;11(3):254-259.

107. Paul JE, Nantha-Aree M, Buckley N, et al. Gabapentin does not improve multimodal analgesia outcomes for total knee arthroplasty: a randomized controlled trial. Can J Anaesth. 2013;60(5):423-431.

108. Paul JE, Nantha-Aree M, Buckley N, et al. Randomized controlled trial of gabapentin as an adjunct to perioperative analgesia in total hip arthroplasty patients. Can J Anaesth. 2015;62(5):476-484. 
109. Prabhakar H, Arora R, Bithal PK, Rath GP, Dash HH. The analgesic effects of preemptive gabapentin in patients undergoing surgery for brachial plexus injury-a preliminary study. $J$ Neurosurg Anesthesiol. 2007;19(4):235-238.

110. Radhakrishnan M, Bithal PK, Chaturvedi A. Effect of preemptive gabapentin on postoperative pain relief and morphine consumption following lumbar laminectomy and discectomy: a randomized, double-blinded, placebo-controlled study. J Neurosurg Anesthesiol. 2005; 17(3): 125-128.

111. Ram B, Khanna R, Kumar M, et al. Pre-emptive gabapentin v/s pregabalin for acute postoperative analgesia following abdominal hysterctomy under spinal anaesthesia: a randomized double blind study. SEAJCRR. 2015;4(5):2031-2034.

112. Basavareddy A, Meher B, Rajendran I, Srinivasan S. Prospective, randomised, double blinded controlled trial of gabapentin and pregabalin as pre emptive analgesia in patients undergoing lower abdominal and limb surgery under spinal anaesthesia. Indian J Pain. 2014;2 $8(3): 155$.

113. Rapchuk IL, O'Connell L, Liessmann CD, Cornelissen HR, Fraser JF. Effect of gabapentin on pain after cardiac surgery: a randomised, double-blind, placebo-controlled trial. Anaesth Intensive Care. 2010;38(3):445-451.

114. Ray D, Bhattacharjee S. Effect of pre-operative gabapentin on early post operative pain, nausea, vomiting and analgesic consumption following hysterectomy in a tertiary care teaching hospital: a randomized controlled trial. Indian J Pharm Pharmacol. 2015;2(2):113-118.

115. Rimaz S, HeiratiA, Nabi BN, et al. Pre-emptive gabapentin versus pregabalin for acute postoperative pain after external dacryocystorhinostomy surgery under regional anesthesia: a randomized placebocontrolled trial. Nautilus. 2014;128(1):43-51.

116. Rorarius MG, Mennander S, Suominen P, et al. Gabapentin for the prevention of postoperative pain after vaginal hysterectomy. Pain. 2004;110(1-2):175-181.

117. Saeed MH, Krikor AW, Yaquob ZA, et al. Preoperative gabapentin in laparoscopic cholecystectomy. Bas J Surg. 2013;19(1):24-29.

118. Sava M, Rusu N. Effects of gabapentin on haemodynamic response to laryngoscopy and tracheal intubation (Efectul gabapentinului asupra răspunsului hemodinamic la laringoscopie şi intubație orotraheală). J Rom Anest Terap Int. 2009;16:114-120.

119. Sekhavet L, Zare F, Mojibian M. The postoperative analgesic effects of low-dose gabapentin in patients undergoing abdominal hysterectomy. SAJOG. 2009;15(1):37-40.

120. Semira A, Zaffar T, Vishal R, Bashir A, Kour K. A prospective, randomized, placebo-controlled, trial comparing the effectiveness of gabapentin, ondansetron \& dexamethasone in prevention of nausea \& vomiting after laparoscopic cholecystectomy. JK Sci. 2013;15:117-121.

121. Sen H, Sizlan A, Yanarates O, et al. A comparison of gabapentin and ketamine in acute and chronic pain after hysterectomy. Anesth Analg. 2009;109(5):1645-1650.

122. Sen H, Sizlan A, Yanarates O, et al. The effects of gabapentin on acute and chronic pain after inguinal herniorrhaphy. Eur J Anaesthesiol. 2009;26(9):772-776.

123. Sharma JP, Bijalwan A, Beg MA, et al. Effect of gabapentin in postoperative pain, nausea and vomiting in patients undergoing laparoscopic cholecystectomy. Int J Med Sci Public Health. 2015;4:565-568.

124. Sheen MJ, Ho ST, Lee CH, Tsung YC, Chang FL. Preoperative gabapentin prevents intrathecal morphine-induced pruritus after orthopedic surgery. Anesth Analg. 2008;106(6):1868-1872.

125. Siddiqui NT, Fischer H, Guerina L, Friedman Z. Effect of a preoperative gabapentin on postoperative analgesia in patients with inflammatory bowel disease following major bowel surgery: a randomized, placebo-controlled trial. Pain Pract. 2014;14(2):132-139.

126. Soltanzadeh M, Ebad A, Pipelzadeh MR, et al. Gabapentin may relieve post-coronary artery bypass graft pain: a double blind randomized clinical trial. Int Cardivasc Res J. 2011;5(3):79-82.
127. Spence D, Goff J, Mohan E, Bowen K, Osborne L, Maye J. Perioperative administration of gabapentin for shoulder arthroscopy: a prospective, randomized, double-blind, placebo-controlled study. AANA J. 2011;79(4 Suppl):S43-S50.

128. Srivastava U, Kumar A, Saxena S, Mishra AR, Saraswat N, Mishra S. Effect of preoperative gabapentin on postoperative pain and tramadol consumption after minilap open cholecystectomy: a randomized double-blind, placebo-controlled trial. Eur J Anaesthesiol. 2010;27(4):331-335.

129. Syal K, Goma M, Dogra RK, Ohri A, Gupta AK, Goel A. "Protective premedication": a comparative study of acetaminophen, gabapentin and combination of acetaminophen with gabapentin for post-operative analgesia. J Anaesthesiol Clin Pharmacol. 2010;26(4):531-536.

130. Tirault M, Foucan L, Debaene B, et al. Gabapentin premedication: assessment of preoperative anxiolysis and postoperative patient satisfaction. Acta Anaesthesiol Belg. 2010;61(4):203-209.

131. Turan A, Karamanlioglu B, Memis D, et al. Analgesic effects of gabapentin after spinal surgery. Anesthesiology. 2004;100(4):935-938

132. Turan A, Kaya G, Karamanlioglu B, Pamukcu Z, Apfel CC. Effect of oral gabapentin on postoperative epidural analgesia. Brit J Anaesth. 2006;96(2):242-246.

133. Turan A, Memis D, Karamanlioglu B, Yagiz R, Pamukcu Z, Yavuz E. The analgesic effects of gabapentin in monitored anesthesia care for ear-nose-throat surgery. Anesth Analg. 2004;99(2):375-378, table of contents.

134. Turan A, White PF, Karamanlioglu B, et al. Gabapentin: an alternative to the cyclooxygenase-2 inhibitors for perioperative pain management. Anesth Analg. 2006;102(1):175-181.

135. Ucak A, Onan B, Sen H, Selcuk I, Turan A, Yilmaz AT. The effects of gabapentin on acute and chronic postoperative pain after coronary artery bypass graft surgery. J Cardiothorac Vasc Anesth. 2011;25(5): 824-829.

136. Vahedi P, Shimia M, Aghamohammadi D, et al. Does preemptive gabapentin reduce morphine consumption and remaining leg pain after lumbar discectomy? Neurosurg Q. 2011;21(2):114-120.

137. Vasigh A, Jaafarpour M, Khajavikhan J, Khani A. The effect of gabapentin plus celecoxib on pain and associated complications after laminectomy. J Clin Diagn Res. 2016;10(3):UC04-UC08.

138. Verma A, Arya S, Sahu S, Lata S, Panday HD, Singh H. To evaluate the role of gabapentin as preemptive analgesic in patients undergoing total abdominal hysterectomy in epidural anaesthesia. Indian $J$ Anaesthesia. 2008;52(4):428-431.

139. Bafna U, Rajarajeshwaran K, Khandelwal M, Verma AP. A comparison of effect of preemptive use of oral gabapentin and pregabalin for acute post-operative pain after surgery under spinal anesthesia. $J$ Anaesthesiol Clin Pharmacol. 2014;30(3):373-377.

140. Waikakul W. Combination of gabapentin and celecoxib for analgesia after major orthopedic surgery: a randomized, controlled trial. Asian Biomed. 2011;5(1):101-110.

141. Yoon K, Kim CS, Ryu KH, et al. Analgesic effects of gabapentin on post-hysterectomy pain. Korean J Anaesthesiol. 2001;41(6):13-18.

142. Zaldivar-Ramirez FR. Eficacia de uso de la gabapentina enel control del dolor, nausea y vomito en el postoperatoriode la funduplicatura laparoscopica tipo nissen. Doctoral dissertation 2011 (assessed 29/12/2014).

143. Clarke H, Pereira S, Kennedy D, et al. Adding gabapentin to a multimodal regimen does not reduce acute pain, opioid consumption or chronic pain after total hip arthroplasty. Acta Anaesth Scand. 2009;53(8):1073-1083.

144. Schulz KF, Chalmers I, Hayes RJ, Altman DG. Empirical evidence of bias. Dimensions of methodological quality associated with estimates of treatment effects in controlled trials. JAMA. 1995;273(5):408-412.

145. Stewart BH, Kugler AR, Thompson PR, Bockbrader HN. A saturable transport mechanism in the intestinal absorption of gabapentin is the underlying cause of the lack of proportionality between increasing dose and drug levels in plasma. Pharm Res. 1993;10(2):276-281. 
146. Dirks J, Petersen KL, Rowbotham MC, Dahl JB. Effect of systemic adenosine on pain and secondary hyperalgesia associated with the heat/capsaicin sensitization model in healthy volunteers. Reg Anesth Pain Med. 2001;26(5):414-419.

147. Mathiesen O, Imbimbo BP, Hilsted KL, Fabbri L, Dahl JB. CHF3381, a N-methyl-D-aspartate receptor antagonist and monoamine oxidase-A inhibitor, attenuates secondary hyperalgesia in a human pain model. J Pain. 2006;7(8):565-574.

148. Gottrup H, Juhl G, Kristensen AD, et al. Chronic oral gabapentin reduces elements of central sensitization in human experimental hyperalgesia. Anesthesiology. 2004;101(6):1400-1408.
149. Chen SR, Eisenach JC, McCaslin PP, Pan HL. Synergistic effect between intrathecal non-NMDA antagonist and gabapentin on allodynia induced by spinal nerve ligation in rats. Anesthesiology. 2000;92(2):500-506.

150. Van Elstraete AC, Tirault M, Lebrun T, et al. The median effective dose of preemptive gabapentin on postoperative morphine consumption after posterior lumbar spinal fusion. Anesth Analg. 2008;106(1):305308 , table of content.

151. Fabritius ML, Geisler A, Petersen PL, Wetterslev J, Mathiesen O, Dahl JB. Gabapentin in procedure-specific postoperative pain management preplanned subgroup analyses from a systematic review with metaanalyses and trials sequential analyses. BMCAnesthesiol. 2017;17(1):85.
Journal of Pain Research

\section{Publish your work in this journal}

The Journal of Pain Research is an international, peer reviewed, open access, online journal that welcomes laboratory and clinical findings in the fields of pain research and the prevention and management of pain. Original research, reviews, symposium reports, hypothesis formation and commentaries are all considered for publication.

\section{Dovepress}

The manuscript management system is completely online and includes a very quick and fair peer-review system, which is all easy to use. Visit http://www.dovepress.com/testimonials.php to read real quotes from published authors. 